\title{
ATIVIDADE ANTIMICROBIANA IN VITRO DO LÁTEX DO AVELOZ (Euphorbia tirucalli L.), PINHÃO BRAVO (Jatropha mollissima L.) E PINHÃO ROXO (Jatropha gossypiifolia L.) SOBRE MICRORGANISMOS PATOGÊNICOS.
}

\author{
Francisco Angelo Gurgel da Rocha \\ Professor do IFRN - Campus Currais Novos. E-mail: angelo.gurgel@cefetrn.br \\ Leandro Ícaro Santos Dantas \\ Aluno do Curso Técnico Integrado em Alimentos e Bolsista de IC \\ IFRN - Campus Currais Novos. E-mail: leandroicarosantos@hotmail.com
}

\section{RESUMO}

Por milênios, o Homem tem explorado a flora como recurso terapêutico. Muitas das espécies medicinais utilizadas possuem fitoquímicos com potencial aplicação no controle do crescimento microbiano. A resistência microbiana crescente representa um sério risco à Saúde Coletiva, sendo necessário o desenvolvimento de projetos que visem a prospecção e/ou o desenvolvimento de novas drogas antimicrobianas. Na Caatinga da Região do Seridó do RN são encontradas as plantas medicinais Jatropha mollissima (Pohl) Baill (Pinhão-bravo), a Jatropha gossypiifolia L (Pinhão-roxo) e Euphorbia tirucalli L (Aveloz), pertencentes à Família Euphorbiaceae, na qual estão presentes fitoquímicos antimicrobianos. O presente projeto objetivou caracterizar a ação antibacteriana do látex destas espécies vegetais contra os patógenos Staphylococcus aureus, Salmonella typhimurium, Salmonella typhi e Listeria monocytogenes. Duplicatas de Placas de Petri contendo ágar Mueller-Hinton foram semeadas em superfície com culturas padronizadas de cada microrganismo. Foram perfurados poços de $10 \mathrm{~mm}$ de diâmetro nos quais se inoculou $100 \mu \mathrm{L}$ das diluições dos látex testados. As placas foram incubadas a $35 \pm 2^{\circ} \mathrm{C} / 24$ h. Os halos de inibição quando existentes foram medidos e registrados. L. monocytogenes apresentou a maior sensibilidade ao látex de J. mollissima; S. aureus foi inibido por $J$. mollissima e J. gossypiifolia, sendo mais sensível no primeiro caso. $S$. typhi e $S$. typhimurium apresentaram os maiores halos de inibição (J. gossypiifolia), sendo S. typhi mais sensível ao látex de J. gossypiifolia e S. typhimurium ao de J. mollissima. E. tirucalli não apresentou atividade inibitória. Padrões de sazonalidade parecem influenciar a capacidade inibitória do látex. Recomendamos que sejam efetuados estudos mais detalhados acerca das propriedades antimicrobianas do látex de $J$. mollissima e $J$. gossypiifolia.

PALAVRAS-CHAVE: atividade antimicrobiana, Jatropha mollissima, Jatropha gossypiifolia, Euphorbia tirucalli, Salmonella, Staphylococcus aureus, Listeria monocytogenes. 


\section{ATIVIDADE ANTIMICROBIANA IN VITRO DO LÁTEX DO AVELOZ (Euphorbia tirucalli L.), PINHÃO BRAVO (Jatropha mollissima L.) E PINHÃO ROXO (Jatropha gossypiifolia L.) SOBRE MICRORGANISMOS PATOGÊNICOS.}

\section{INTRODUÇÃO}

A História das comunidades humanas tem refletido uma busca incessante por melhorias na qualidade de vida de seus integrantes. Nessa busca, a Fauna e a Flora têm fornecido por milênios as matérias-primas para a elaboração de abrigos, peças de vestuário, cosméticos e medicamentos. As espécies vegetais utilizadas para finalidades terapêuticas são genericamente denominadas "plantas medicinais”. Nos últimos anos, muitas das suas aplicações têm sido validadas cientificamente, relacionando-se a presença de certos fitoquímicos à sua atividade terapêutica indicada na Medicina Tradicional.

É bem conhecido que a eficácia terapêutica de uma planta medicinal não advém de um simples grupo de compostos, mas de uma grande variedade de fitoquímicos denominado "fitocomplexo", cuja composição pode ser influenciada por fatores endógenos ou exógenos ao vegetal (CAPASSO et al., 2000). Dada a grande variação de composição bioquímica e concentração de componentes bioativos no fitocomplexo, é esperado que uma mesma planta medicinal possa apresentar dezenas (e ate centenas) de atividades biológicas distintas e em muitos casos, antagônicas entre si (UNITED STATES DEPARTMENT OF AGRICULTURE, 2009). Potencialmente, toda substância, independente de sua proporção no vegetal e de ser ou não conhecida, pode ser um princípio ativo (FILHO; YUNES, 1998).

Diante da megadiversidade brasileira, a possibilidade de utilização de fitoquímicos no desenvolvimento de novos produtos é uma perspectiva animadora em face à resistência bacteriana aos antibióticos. Remontando à década de 50, o fenômeno resulta do uso indiscriminado destas drogas, sendo que a ineficácia crescente de tais quimioterápicos constitui um problema crescente para a Saúde Coletiva, interferindo diretamente sobre o controle de microrganismos patogênicos (BACCARO et al., 2002; NAWAZ, 2002). Dentre as espécies de patógenos que apresentam cepas resistentes, destacamos o Staphylococcus aureus, Salmonella typhi, Salmonella typhimurium e Listeria monocytogenes. Com base nisso, a presença de tais microrganismos em alimentos e superfícies de trabalho é uma preocupação prioritária para a Saúde Coletiva (BACCARO et al., 2002; GAYOSO et al., 2007; RAPINI et al., 2007; MANTILLA et al., 2008; RIBEIRO et al., 2006).

É consenso na comunidade acadêmica que iniciativas que visem a prospecção de novas drogas antimicrobianas em plantas medicinais, possibilitam o desenvolvimento de moléculas mais eficientes no controle de microrganismos resistentes aos quimioterápicos convencionais. É reconhecido mundialmente que certas espécies vegetais possuem em seu fitocomplexo substâncias químicas com ação inibitória sobre microrganismos patogênicos (FRANZENER et al., 2007; CORDEIRO et al., 2006; FENNER et al.,2006; LIMA et al., 2006; SILVA et al., 2007, SOARES et al., 2007, USHIMARU e al., 2007). Dentre as espécies vegetais potencialmente úteis ao controle de microrganismos resistentes aos antibióticos encontradas na Região do Seridó do Rio Grande do Norte estão a Jatropha mollissima (Pohl) Baill - pinhão-bravo, Jatropha gossypiifolia L - pinhão-roxo e Euphorbia tirucalli L - Aveloz (MATOS, 1987), espécies lactescentes pertencentes à 
Família Euphorbiaceae (BRAGA, 1960; BARG, 2004; BRASILEIRO et al., 2006). A Família Euphorbiaceae é um objeto interessante de estudo, já que existem relatos da presença de princípios ativos antibacterianos como apigenina, $\beta$-sitosterol, taninos, ácido cítrico, ácido elágico e ácido málico em várias de suas espécies (UNITED STATES DEPARTMENT OF AGRICULTURE, 2009). Apesar de seu potencial uso como fonte de antimicrobianos, as espécies mencionadas têm sido alvos de pouco ou nenhum estudo no tocante às suas propriedades antibacterianas: levantamento bibliográfico indicou a existência de trabalhos acerca de ação antibacteriana de E. tirucalli (MOHANA et al., 2008; PARECH et al., 2007). J. mollissima e J. gossypiifolia, no entanto, não aparentam ter sido objeto de pesquisas com esta finalidade. Portanto, inexistem estudos comparativos da ação antibacteriana in vitro das três espécies.

O presente trabalho objetivou caracterizar a atividade antibacteriana do látex das espécies vegetais mencionadas sobre os patógenos Staphylococcus aureus, Salmonella typhi, Salmonella typhimurium e Listeria monocytogenes, comparando a efetividade de sua ação, bem como a influencia sazonal sobre o efeito inibitório.

\section{METODOLOGIA}

Conforme a classificação de Gil (1991) utilizou-se uma abordagem Experimental, na qual se avaliou a ação do látex dos vegetais referenciados sobre os microrganismos-alvo descritos.

\section{Espécies medicinais estudadas, parte coletada e área da coleta.}

Foram testadas amostras do látex obtido a partir de Jatropha mollissima (Pohl) Baill (Pinhão-Bravo), Jatropha gossypiifolia L (Pinhão-Roxo) e Euphorbia tirucalli L (Aveloz). Os espécimes estudados foram selecionados e identificados, no município de Cruzeta (06²4’43,2” Sul; 3647’24,0” Oeste) e Acari (06²6’9,6” Sul; 36³8’20” Oeste), ambos situados na mesorregião Central Potiguar e na microrregião Seridó Oriental, com clima

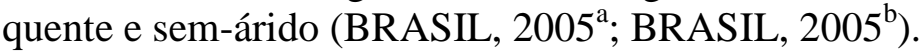

\section{Coleta das amostras}

Após a seleção do espécime e sua correta identificação botânica, foram coletados cerca de $10 \mathrm{~mL}$ de látex (para cada uma das repetições), utilizando-se para tanto ação mecânica lesiva aos tecidos vegetais. O material foi recolhido em tubos de ensaio com tampa rosqueável estéreis, identificados por etiqueta contendo: nome da espécie, data da coleta e nome do coletor. O mesmo exemplar foi utilizado para as coletas subsequentes. Os tubos contendo as amostras de látex devidamente identificados foram envolvidos em papel alumínio e encaminhados ao Laboratório de Alimentos do IFRN - Campus Currais Novos, onde foram mantidos sob refrigeração a $10^{\circ} \mathrm{C}$ e protegidos da luz até o momento da sua utilização nos experimentos, obedecendo ao prazo máximo de 48 horas para o início dos experimentos.

\section{Preparo das Diluições Seriais}

Utilizando-se solução salina estéril, foram preparadas diluições seriais do látex de cada uma das espécies, com concentrações de 100\% (não diluído), 80\%, 60\%, 40\%, 20\%, 10\%. As diluições foram acondicionadas individualmente em frascos fechados e identificados, protegidos da incidência de luz e mantidos sob refrigeração a $10^{\circ} \mathrm{C}$ até o momento de sua utilização. 


\section{Microrganismos-alvo}

A atividade antibacteriana das espécies vegetais estudadas foi testada sobre os microrganismos Listeria monocytogenes, Staphylococcus aureus (ATCC 25923), Salmonella typhi, Salmonella typhimurium. As culturas puras foram obtidas a partir da bacterioteca do IFRN Campus Currais Novos.

\section{Padronização do inoculo}

Os inóculos foram padronizados utilizando-se o padrão 0,5 da escala de McFarland. Os microrganismos foram inoculados em tubos de ensaio contendo caldo BHI estéril e incubados a $37^{\circ} \mathrm{C}$ em condições aeróbias por 2 a 6 horas, após o que foram comparados ao padrão McFarland 0,5. Quando necessário, a turbidez da cultura foi ajustada com uso de solução salina estéril, imediatamente antes da semeadura nas placas (ALVES et al., 2008; NCCLS, 2003).

\section{Inoculação das Placas de Teste}

Foram utilizadas placas de Petri de $180 \mathrm{~mm}$ de diâmetro, contendo cerca de $60 \mathrm{~mL}$ de ágar Mueller-Hinton, previamente identificadas. As placas foram semeadas pelo método spread plate, com utilização de swab estéril. Para cada espécie de microrganismo foram inoculadas placas em duplicata. As placas foram mantidas entreabertas na Cabine de Segurança Biológica pelo tempo máximo de 5 minutos, permitindo a absorção/evaporação do excesso de umidade (NCCLS, 2003).

\section{Teste de difusão em ágar e leitura dos resultados}

Em cada uma das placas semeadas, foram perfurados 7 poços, sendo um deles central e os demais periféricos. A distância mínima entre os poços foi de aproximadamente $20 \mathrm{~mm}$. Para cada poço foi transferido $100 \mu \mathrm{l}$ do látex puro de cada espécie e de suas diluições progressivas (VALGAS, 2007). O controle positivo foi inoculado no poço central, ao qual foi adicionado $100 \mu \mathrm{l}$ de Cloranfenicol $(4 \mathrm{mg} / \mathrm{mL})$. As placas foram incubadas a $37^{\circ} \mathrm{C} / 24 \mathrm{~h}$ em condições aeróbias, após o que se verificou a ocorrência de crescimento uniforme dos microrganismos e a presença de halo de inibição. Os diâmetros dos halos foram mensurados com uso de paquímetro, incluindo-se nestes o valor correspondente aos poços. (NCCLS, 2003).

\section{RESULTADOS}

Os dados referentes ao espectro de ação das espécies vegetais sobre os microrganismosalvo, são descritos nas tabelas 1 e 2 .

Os maiores halos de inibição gerados foram obtidos a partir dos látex não-diluídos de $J$. mollissima (L. monocytogenes, $20 \mathrm{~mm}$; S. typhimurium, $20 \mathrm{~mm}$ ) e J. gossypiifolia (S. typhi, $25 \mathrm{~mm}$; S. typhimurium, $22 \mathrm{~mm}$ ).

Os dados obtidos permitem estabelecer que L. monocytogenes é mais sensível ao látex de J. gossypiifolia. Embora o halo obtido com o látex não-diluído de J. mollissima tenha sido maior (tabela 1), observou-se que a inibição do microrganismo ocorre em concentração quatro vezes menor quando exposto ao látex de $J$. gossypiifolia (tabela 2). Isto provavelmente deve-se às possíveis diferenças na composição química dos látex testados. 
Tabela 1: Diâmetro dos maiores halos de inibição observados, obtidos a partir de frações do látex não-diluído (JM= Jatropha mollissima; JG = Jatropha gossypiifolia; ET= Euphorbia tirucalli).

\begin{tabular}{|c|c|c|c|c|c|}
\hline \multirow[t]{2}{*}{ Microrganismo } & \multirow[t]{2}{*}{ Período } & \multicolumn{3}{|c|}{$\begin{array}{c}\text { Espécie } \\
\text { vegetal/Halo } \\
\text { de inibição }(\mathbf{m m})\end{array}$} & \multirow[t]{2}{*}{$\begin{array}{l}\text { Controle + } \\
\text { Cloranfenicol } \\
\quad(\mathrm{mm})\end{array}$} \\
\hline & & $\mathbf{J M}$ & JG & ET & \\
\hline \multirow[t]{2}{*}{ Listeria monocytogenes } & Chuvoso & 20 & 15 & - & 36 \\
\hline & Seco & 15 & 17 & - & 35 \\
\hline \multirow[t]{2}{*}{ Staphylococcus aureus } & Chuvoso & 14 & - & - & 33 \\
\hline & Seco & 15 & 15 & - & 33 \\
\hline \multirow{2}{*}{$\begin{array}{l}\text { Salmonella } \\
\text { typhi }\end{array}$} & Chuvoso & 18 & 25 & - & 31 \\
\hline & Seco & 12 & - & - & 30 \\
\hline \multirow[t]{2}{*}{ Salmonella typhimurium } & Chuvoso & 20 & 22 & - & 39 \\
\hline & Seco & 12 & - & - & 38 \\
\hline
\end{tabular}

S. aureus foi inibido por J. mollissima, e por J. gossypiifolia, sendo que halo desta última foi obtido a partir do látex do período seco. A amostra coletada durante o período chuvoso não apresentou inibição contra o microrganismo.

S. typhi e S. typhimurium apresentaram os maiores halos de inibição, quando expostos ao látex de $J$. gossypiifolia (tabela 1). S. typhi mostrou-se mais sensível ao látex testado de desta espécie, enquanto $S$. typhimurium ao de $J$. mollissima (tabela 2), com inibição de crescimento frente às diluições mais elevadas.

Verificou-se que dentre as espécies vegetais testadas, o látex de J. mollissima apresentou o espectro de ação mais amplo, inibindo o crescimento de todos os microrganismos-alvo e mantendo a sua atividade inibitória, com variações, tanto no período chuvoso quanto no seco. O látex de J. gossypiifolia mostrou-se como o segundo mais efetivo. Os resultados apontam para uma possível influência da disponibilidade hídrica sobre as propriedades inibitórias dos látex de J. mollissima e J. gossypiifolia (tabela 1, tabela 2 e figura 1).

É razoável hipotetizar que tais diferenças na atividade inibitória das amostras de látex devam-se às variações na composição química dos mesmos, uma vez que o fitocomplexo é afetado pelas diversas interações ecológicas às quais as espécies vegetais estão submetidas em seus ambientes, dentre as quais estão o estresse hídrico e o clima (CAPASSO et al., 2000).

A atividade inibitória relatada por Mohana et al (2008) e Parech et al (2007) para os extratos aquoso e metanólico de E. tirucalli, não foi observada em seu látex. Isto pode dever-se tanto à utilização do látex in natura e diluído ao invés dos extratos mencionados, quanto pelas possíveis variações na composição do fitocomplexo já discutidas. 
Tabela 2: menores concentrações nas quais se observou halo de inibição (JM= Jatropha mollissima; JG = Jatropha gossypiifolia).

\begin{tabular}{|l|l|c|c|}
\hline \multirow{2}{*}{ Microrganismo } & \multicolumn{3}{|c|}{ Diluição Inibitória Mínima/Espécie } \\
\cline { 2 - 4 } & \multicolumn{1}{|c|}{ Período } & JM & JG \\
\hline \multirow{2}{*}{ Listeria monocytogenes } & Chuvoso & $40 \%$ & $10 \%$ \\
\cline { 2 - 4 } & Seco & $40 \%$ & $10 \%$ \\
\hline \multirow{2}{*}{ Staphylococcus aureus } & Chuvoso & $60 \%$ & - \\
\cline { 2 - 4 } & Seco & $20 \%$ & $10 \%$ \\
\hline \multirow{2}{*}{ Salmonella typhi } & Chuvoso & $60 \%$ & $40 \%$ \\
\cline { 2 - 4 } & Seco & $60 \%$ & $40 \%$ \\
\hline \multirow{2}{*}{ Salmonella typhimurium } & Chuvoso & $40 \%$ & $60 \%$ \\
\cline { 2 - 4 } & Seco & $60 \%$ & - \\
\hline
\end{tabular}

\section{Espectro de inibição $\mathrm{x}$ disponibilidade hídrica}

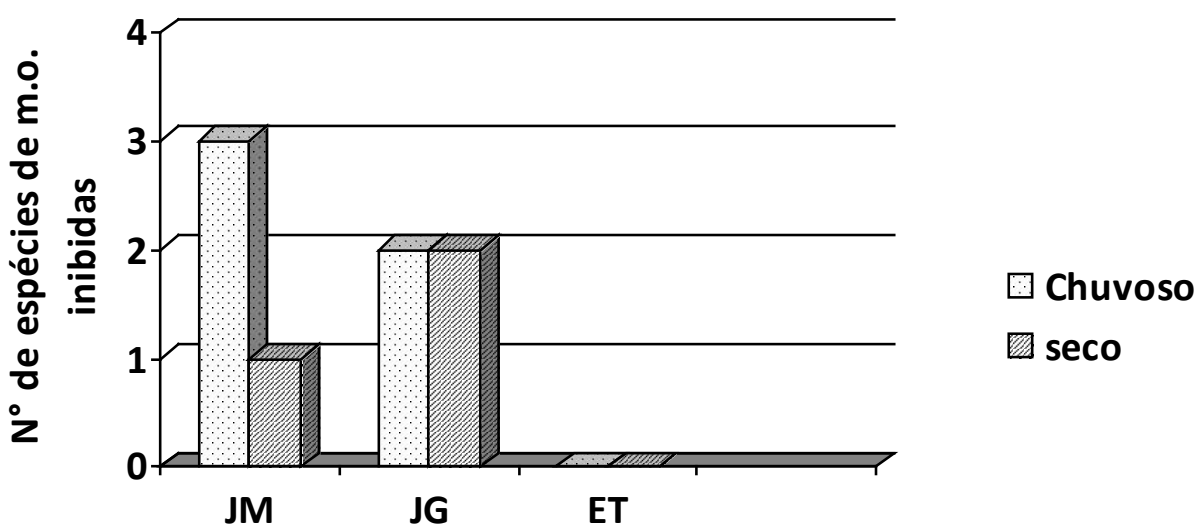

Espécies vegetais

Figura 1: maiores respostas inibitórias observadas (látex nãodiluído) relacionadas ao período de coleta correspondente (JM= Jatropha mollissima; JG = Jatropha gossypiifolia; ET= Euphorbia tirucalli).

\section{CONCLUSÕES}

L. monocytogenes apresentou a maior sensibilidade ao látex de J. mollissima; S. aureus foi inibido por J. mollissima e J. gossypiifolia, sendo mais sensível a esta última. S. typhi e S. typhimurium foram os microrganismos que apresentaram maiores halos de inibição ( $J$. gossypiifolia), sendo que $S$. typhi é mais sensível ao látex de $J$. gossypiifolia, enquanto $S$. typhimurium ao de J. mollissima. E. tirucalli não apresentou qualquer atividade sobre os microrganismos testados. J. mollissima inibiu todos os patógenos, tanto no período chuvoso, quanto no seco. A disponibilidade hídrica parece ser um fator determinante para a presença de atividade inibitória no látex das espécies vegetais estudadas. Diante dos resultados obtidos, propomos que sejam realizados estudos mais detalhados acerca das propriedades antimicrobianas do látex de J. mollissima e J. gossypiifolia. 


\section{REFERÊNCIAS BIBLIOGRÁFICAS}

ALVES, E. G.; VINHOLIS, A. H. C.; CASEMIRO, L. A.; JACOMETTI, N. A.; FURTADO, C.; MARTINS, C. H. G.. Estudo comparativo de técnicas de screening para avaliação da atividade antibacteriana de extratos brutos de espécies vegetais $e$ de substâncias puras. Quim. Nova. V 31, n5, p1224-1229, 2008.

BACCARO, M. R.; MORENO, A. M.; CORRÊA, A.; FERREIRA, A. J. P.; CALDERARO, F. F.. Resistência antimicrobiana de amostras de Escherichia coli isoladas de fezes de leitões com diarréia. Arq. Inst. Biol., São Paulo, v 69, n 2, p 15-18, abr-jun, 2002.

BARG, Débora Gikovate. Plantas tóxicas. Monografia. IBEHE/FACIS. São Paulo, 2004. Disponível em http://www.esalq.usp.br/siesalq/pm/plantas_toxicas.pdf. Acesso em 31/03/2009.

BRAGA, Renato. Plantas do Nordeste, especialmente do Ceará. 5 . ed. Mossoró: Fundação Vingt-Un Rosado, 1960.

BRASIL. MINISTÉRIO DAS MINAS E ENERGIA. Projeto de fontes de abastecimento por água subterrânea no Estado do Rio Grande do Norte: Diagnóstico do Município de Acari. Recife, $2005^{\mathrm{a}}$.

BRASIL. MINISTÉRIO DAS MINAS E ENERGIA. Projeto de fontes de abastecimento por água subterrânea no Estado do Rio Grande do Norte: Diagnóstico do Município de Cruzeta. Recife, $2005^{\mathrm{b}}$.

BRASILEIRO, Beatriz Gonçalves; Pizziolo, Virgínia Ramos; RASLAM, Délio Soares; JAMAL, Cláudia M.; SILVEIRA, Damaris. Antimicrobial and cytotoxic activities screening of some brazilian medicinal plants used in Governador Valadares District. Revista Brasileira de Ciências Farmacêuticas. V 42, n 2, 2006.

CAPASSO, R,; IZZO, A.A.; PINTO, L; BIFULCO, T,; VITOBELLO, C.; MASCOLO, N. Phytotherapy and quality of herbal medicines. Fitoterapia, n. 71, p. 58, 2000.

CORDEIRO, C. H. G.; SACRAMENTO, L. V. S,;CORRÊA, M. A.; PIZZOLITTO, A. C.; $B A U A B$, . M.. Análise farmacognóstica e atividade antibacteriana de extratos vegetais empregados em formulação para a higiene bucal. Brazilian journal of Pharmaceutical Sciences. V 42, n 3, jul-set, 2006.

FENNER, R.; BETTI, A. H.; MENTZ, L. A.; RATES, S. M. K.. Plantas utilizadas na medicina popular com potencial atividade antifúngica. Brazilian journal of Pharmaceutical Sciences. V 42, n 3, jul-set, 2006.

FILHO, Valdir Chechinel; YUNES, Rosendo, A..Estratégias para a obtenção de compostos farmacológicamente ativos a partir de plantas medicinais. Conceitos sobre a modificação estrutural para otimização da atividade. Química nova, 21, 1. 1998. 
FRANZENER, G.; MARTINEZ-FRANZENER, A. da Silva.; STANGARLIN, J. R.; CZEPAK, M. P.; SCHWAN-ESTRADA, K. R. F.; CRUZ, M. E. S.. Antibacterial, antifungal and phytoalexins induction activities of hydrolates of medicinal plants. Semina: ciências Agrárias, Londrina, v 28, n 1, p 29-38. jan-mar 2007.

GAYOSO, M. de Fátima A.; OLIVEIRA, A. D. D.; D 'AZEVEDO, P. A.; YU, M. C. Z.; HOFLING-LIMA, A. L.. FRANCISCO, W. Suscetibilidade antimicrobiana in vitro dos Staphylococcus coagulase negativa oculares. Arq. Bras. De Oftalmo., 70, 2007.

GIL, Antônio Carlos. Como elaborar projetos de pesquisa. São Paulo: Atlas S. A. , 1991.

LIMA, M. R. F.; XIMENES, E. C. P.; LUNA, J. S.; SAT’ANA, A. E. G.. The antibiotic activity of some medicinal plants. Brazilian journal of pharmacognosy. V 16, n 3, p 300306, jul-set 2006.

MANTILLA, S. P. S.; FRANCO, R. M.; OLIVEIRA, L. A. T. de Oliveira; SANTOS, E. B.; GOUVEAA, R.. Resistência antimicrobiana de bactérias do gênero Listeria spp. Isoladas de carne moída bovina. Braz. J. Vet. Res. Anim. Sci. V 45, n 2, p 116-121, 2008.

MATOS, F. J. de Abreu. O formulário fitoterápico do professor Dias da Rocha. Coleção ESAM, ano XX, v 18. Coleção Mossoroense. Mossoró, RN, 1987.

MOHANA, D. C.; SATISH, S.; RAVESHA, K. A.. Antibacterial evaluation of some plant extract against some human pathogenic bacteria. Advances in biological research 2 (3-4): 49 -55, 2008.

NAWAZ, M.S. Human health impact and regulatory issues involving antimicrobial resistance in the food animal production environment. Disponível em: http://www.fda.gov. Acesso em 22 out 2002.

NCCLS. Performance standards for antimicrobial disk susceptibility tests: approved standard. 8 ed. NCCLS Document M2-A8. Pensylvania, USA, 2003.

PAREKH, Jigna; CHANDRA, Sumitra V.; In vitro antimicrobial activity and phytochemical analysisof some Indian medicinal plants. Turk. J Biol. 2007.

RAPINI, L. S.; TEIXEIRA, J. P.; MARTINS, N. E.; CERQUEIRA, M. M. O. P.; SOUZA, M. R.; PENNA, C. F. A. M.. Perfil de resistência antimicrobiana de cepas de Staphylococcus sp. Isoladas de queijo tipo coalho. Arq. Bras. Méd. Vet. Zootec.. v 56, n1 , p 130-133, 2004.

RIBEIRO, A. R.; KELLERMANN, A.; SANTOS, L. R.; FITTÉL, A.P.; NASCIMENTO, V. P.. Resistência antimicrobiana em Salmonella enterica subsp enterica sorovar hadar isoladas de carcaças de frango. Arq. Inst. Biol. V 73, n 3, p 357-360. jun-set, 2006.

SILVA, J. G. da; SOUZA, I. A.; HIGINO, J. S.; SIQUEIRA-JÚNIOR, J. P.; PEREIRA, J. V.; PEREIRA, M. S. V.. Atividade antimicrobiana do extrato de Anacardium 
occidentale Linn. Em amostras multiresistentes de Staphylococus aureus. Revista brasileira de farmacognosia. 17(4): 572-577, out-dez 2007.

SOARES, D. G. S.; OLIVEIRA, C. B.de; LEAL, C.; DRUMOND, M. R S.; PADILHA, W. W. N.. Atividade antibacteriana in vitro da tintura de aroeira (Schinus terebinthifolius) na descontaminação de escovas dentais contaminadas pelo S. mutans. Pesq Brás Odontoped Clin Integ. João Pessoa, 7(3): 253-257, set-dez 2007.

USHIMARU, P. I.; SILVA, M. T. Nogueira da; DI STASI, L. C.; BARBOSA, L.; JÚNIOR, A F.. Antibacterial activity of medicinal plant extracts. Brazilian Journal of Microbiology. 38: 717-719. 2007.

UNITED STATES DEPARTMENT OF AGRICULTURE - USDA. Dr. Duke's phytochemical and etnobotanical databases. Base de dados. Disponível em: http://www.ars-grin.gov/duke/. Acesso em: 06 abr 2009.

VALGAS, C.; SOUZA, S. M de. SMÂNIA, E. F. A.; SMÂNIA JUNIOR, A.. Screening methods to determine antibacterial activity of natural products. Brazilian Journal of microbiology. 38: 369-380. 2007. 